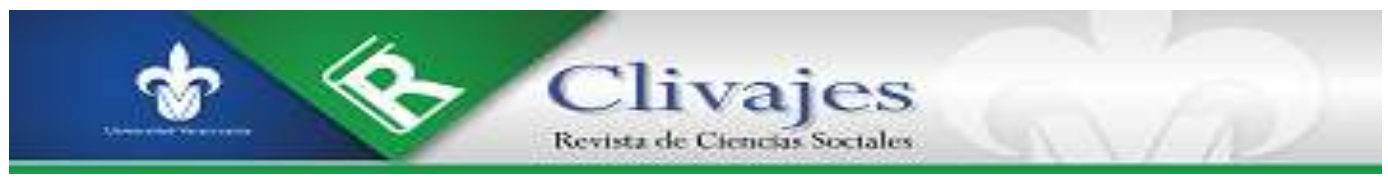

Isaac de Jesús Palazuelos Rojo

REDES SOCIODIGITALES

COMO ESPACIOS SUBALTERNOS DE ENUNCIACIÓN POLIITICA

Clivajes. Revista de Ciencias Sociales. Año VII, número 13, enero-junio 2020, pp. 80-97.

https://clivajes.uv.mx/index.php/Clivajes/editor/proofGalley/2652/4464

Instituto de Investigaciones Histórico-Sociales, Universidad Veracruzana

Clivajes. Revista de Ciencias Sociales/ISSN: 2395-9495/IIH-S, UV/Xalapa, Veracruz, México

Recibido: $18 / 12 / 2019$

Aceptado: $10 / 01 / 2020$

Dictaminado: 02/03/2020

Clivajes. Revista de Ciencias Sociales (ISSN: 2395-9495), Año VII, Núm. 13, enero-junio, 2020 


\title{
REDES SOCIODIGITALES \\ COMO ESPACIOS SUBALTERNOS DE ENUNCIACIÓN POLÍTICA
}

\author{
Isaac de Jesús Palazuelos Rojo*
}

\begin{abstract}
Resumen
En este artículo abordamos la apropiación política de redes sociodigitales en los procesos electorales de 2012 y 2018 en México, con el objeto de reflexionar en torno a los actuales procesos de participación política, que se distinguen por nuevas formas de interacción digital. Partimos de la idea de que, a través del uso de redes, las y los individuos que tradicionalmente permanecían ajenos a la producción y difusión de contenidos audiovisuales disponen de espacios subalternos de enunciación política, desde los cuales visibilizan sus experiencias, al tiempo que son capaces de contribuir en la construcción social de la realidad política, auspiciada por un papel cada vez más preponderante de las narrativas mediáticas.
\end{abstract}

Palabras clave: Redes sociodigitales, Subalternidad, Contenidos audiovisuales

\section{INTRODUCCIÓN}

La apropiación política de las redes sociodigitales ha dado lugar a una gran producción de artículos y libros académicos que han popularizado el concepto tecnopolítica (Toret, 2013). Reiteradamente aparece la idea de que el uso de tales herramientas facilita la deliberación autónoma, por lo que en ocasiones se cae en determinismos tecnológicos, dando por hecho que el solo uso de redes genera movilizaciones políticas descentralizadas y apartidistas. Las interpretaciones más optimistas consideran, incluso, que los discursos contrahegemónicos contenidos en plataformas como Facebook y Twitter pueden ganar terreno y posicionarse como parte importante en la configuración de las narrativas mediáticas. Por nuestra parte, argumentamos que las redes sociodigitales son un espacio alternativo para la difusión de tales discursos, y aunque representan una oportunidad para la deliberación autónoma, persiste una remanencia de la condición subalterna de sus protagonistas.

Partimos de la pregunta planteada por la filósofa india Gayatri Chakravorty Spivak (2003): ¿puede hablar el subalterno? Retomamos dos de los ejes de discusión trazados

\footnotetext{
* Profesor-investigador en las universidades Durango Santander y Tecmilenio; es doctor en Estudios Culturales por el Colegio de la Frontera Norte, maestro en Ciencias Sociales y licenciado en Sociología por El Colegio de Sonora, México.
} 
por la autora, para construir la respuesta a dicha interrogante. Por un lado, la idea de que los grupos subalternos carecen de espacios de enunciación; por otro, la necesidad de representación o mediación por parte de actores hegemónicos que hablan en nombre de los grupos subalternos. Lo anterior se vincula con dos de los mecanismos de exclusión que establece Foucault (1992), en su análisis de discurso en relación con el ejercicio de poder; la "palabra prohibida" y la "voluntad de verdad”. A partir de estos tres conceptos, ${ }^{1}$ reflexionamos sobre la participación política de los ciudadanos a través del uso de redes sociodigitales.

Planteamos que en México existen grupos subalternos compuestos por mujeres, jóvenes, trabajadores, campesinos y etnias con poca cercanía y escaso dominio de los espacios de enunciación política, en el sentido mediático, y que su voz es "representada" u opacada por otros grupos hegemónicos, como los partidos políticos, las instituciones académicas o los medios informativos. Apreciamos dos factores que permiten vislumbrar dicho fenómeno: 1) el esquema de democracia representativa que rige la organización de las esferas pública y política en México; 2) el sistema de concesiones en materia de telecomunicación y el consecuente dominio mediático por parte de grandes monopolios de medios de comunicación.

Más allá de la representatividad política, los movimientos sociales son una de las pocas formas de participación que tales grupos tienen en relación con la elaboración de políticas públicas y la toma de decisiones (Tilly, 2010). El debate contemporáneo sobre las movilizaciones políticas incorpora, en ocasiones con gran entusiasmo, el manejo de las redes sociodigitales como espacios estratégicos de comunicación y de organización autónoma (Toret, 2013). Sin embargo, más recientemente observamos un discurso opuesto, en el que se plantea una visión distinta que denuncia una serie de mecanismos de dominación, de control social y político, que se vislumbra como un panóptico digital (Ventura, 2018).

En las próximas páginas, nos proponemos replantear la pregunta de Spivak (2003), en el contexto de los procesos electorales de 2012 y 2018 en México, con la finalidad de generar una nueva reflexión en torno a la capacidad que tienen los grupos subalternos de hablar y ser escuchados, en un entorno social emergente donde las dimensiones off y on line se ensamblan de manera compleja, dando lugar a una ecología mediática (Milan y Treré, 2017), en la que los medios digitales tienen un papel relevante, con respecto a la configuración de los contextos de participación política ciudadana.

\footnotetext{
${ }^{1}$ Subalternidad, palabra prohibida y voluntad de verdad.
} 
Tomamos como punto de partida una revisión de literatura académica vinculada al análisis del uso de redes sociodigitales en contextos políticos; combinamos estas reflexiones con los postulados de la condición subalterna propuesta por Spivak (2003), y los mecanismos de control discursivo desarrollados por Foucault (1992). Conectamos esta reflexión teórica con el fenómeno de los movimientos sociales en la era de Internet, recurriendo a reflexiones derivadas de un trabajo de campo basado en etnografía digital en torno a los procesos electorales del 2012 y 2018 en México.

\section{LA CUESTIÓN SUBALTERNA}

A finales de la segunda década del siglo XX, Gramsci planteó por primera vez la noción de subalternidad. Según Modonesi (2002), esta expresión fue usada por el autor para referirse a experiencias subjetivas de grupos sociales subordinados por una relación de dominación capitalista. Afirma que el concepto no fue ampliamente desarrollado en la teoría gramsciana, sino que apareció sólo como una contraparte del concepto de hegemonía. Gramsci $(1987,1967)$ propuso el concepto de hegemonía como predominio de las clases dominantes a través de una imposición cultural, mediante la cual se implanta una idea de sociedad a las clases dominadas. Desde la visión gramsciana, se entiende por hegemonía el modo en que las clases dominantes se imponen a grupos subalternos a través de la economía, la política, la educación, la religión y los medios de comunicación.

Este pensador italiano contribuyó al pensamiento marxista con la filosofía de la praxis; la cual definió como el territorio donde se unen la idea y la acción, con el objetivo de fundar una noción de contrapoder basada en una filosofía contrahegemónica, la cual sería útil a los grupos subalternos para confrontar la hegemonía impuesta por las clases dominantes. Dicha visión plantea la necesidad de contrarrestar la cultura hegemónica, para transformar las relaciones sociales mediante una reforma intelectual y moral en beneficio de un desarrollo social equitativo.

A mediados de los ochenta, Spivak lanzó su pregunta: “¿puede hablar el subalterno?", cuestionamiento que dio lugar a un ensayo clásico de la teoría social contemporánea (Giraldo 2003), particularmente con respecto a la corriente de pensamiento postcolonialista, sumándose a los estudios subalternos como una nueva disciplina en el campo de las ciencias sociales. Con tal interpelación, la autora indaga sobre las capacidades de expresión y las posibilidades de ser escuchado de que disponen los grupos sociales más desfavorecidos, a los que denomina subalternos y en los cuales distingue a las mujeres, las etnias, los obreros, los migrantes y los campesinos. 
En su análisis, Spivak (2003) construye una crítica al pensamiento occidental; señala que los intelectuales (franceses, en su mayoría), a pesar de que se auto-adscriben a un posicionamiento de izquierda, toman la palabra del subalterno para expresar su propio discurso como pensadores. De esta manera, lejos de dar voz a las y los sujetos de estudio, les han exotizado y desubjetivado, acentuando su subalternidad, al tiempo que reforzado el pensamiento colonial. La autora entiende este proceso como una cosificación en la que las y los sujetos son tratados como objetos de estudio antropológico; acusa un distanciamiento entre el pensamiento occidental y el no occidental; plantea que el primero es representativo y promueve la invisibilidad de las voces vernáculas, mientras que el segundo reintroduce las propias formas subalternas de enunciación.

Desde este enfoque, el pensamiento europeo no es capaz de superar la noción de la otredad, ya que eso implicaría generar concepciones distintas sobre los grupos estudiados, dejar de verlos como un otro y comprenderlos como una unidad en sí mismos. En la medida que la otredad no pueda ser vista como sujeto en sí mismo, es imposible distinguir en ella la capacidad de razonar o de hablar; tampoco es posible desligarse de la errónea idea de que es necesario hablar en nombre de los grupos vulnerables. Estos aspectos dificultan reconocer las propias representaciones y la propia consciencia de los grupos subalternos. La falta de dicho reconocimiento genera un falso sentido de superioridad, así como una auto-adjudicación del orden civilizatorio. Spivak (2003) plantea la existencia de dos polos: el de los pensadores que tienen acceso a los lenguajes racionales occidentales y el de la subalternidad excluida del lenguaje clarificador de occidente.

De esta manera, la subalternidad se entiende como falta de agencia, como imposibilidad de hablar y ser escuchado. La expresión a la que alude Spivak (2003), remite al dialogo en espacios legitimados por el lenguaje racional occidental: foros académicos, parlamentos o cámaras legislativas. De acuerdo con la autora, a medida que el subalterno desarrolla la agencia de hablar y ser escuchado en estos espacios, tiende a alejarse de su condición original, ya que, para participar de este intercambio dialógico, es necesario apropiarse de una racionalización discursiva que no le es propia y no corresponde plenamente con su consciencia ni sus esquemas de auto-representación.

Por ejemplo, cuando se habla de las mujeres en espacios institucionales de legislación y diseño de políticas públicas o foros de análisis académico que se transmiten mayormente por televisión, es posible que no haya mujeres presentes o que las presente no representen fielmente la condición de vulnerabilidad ni el sentir de este grupo; lo mismo ocurre con la juventud y los pueblos indígenas. Aunque la intención de estos 
espacios parta de reconocer la necesidad de plantear soluciones a las diversas problemáticas que padecen tales grupos, se tiende a caer en esquemas de representatividad antes que dar cabida a la voz vernácula. ${ }^{2}$

Los miembros de los grupos subalternos se ven obligados a apropiarse de los esquemas de lenguaje usados en los espacios mediáticos, legislativos o académicos, para poder hacer uso de la palabra, lo cual termina alejándolos de los modos en que solían expresar su propia realidad. En México, el movimiento \#YoSoy132 reclamaba la hegemonía mediática en las narrativas del proceso electoral de 2012, definiendo como uno de sus principales adversarios a la empresa de medios Televisa. Paradójicamente, el movimiento perdió gran parte de su credibilidad cuando su vocero, Antonio Attolini, apareció al frente de un programa de noticias en Televisa. Muchos de los manifestantes no solamente no se sintieron representados, sino que negaron la idea de que un vocero los representara y además hiciera uso de los medios en contra de los cuales se manifestaban.

Los actores, legitimados por el manejo del discurso racional ordenador, buscan representar y hablar en nombre de los grupos subalternos, a fin de autoafirmar su propia visión o su dominio de la realidad y la organización social. De esta manera, la exposición representativa del subalterno constituye una negación a su consciencia y autorepresentación. La crítica desarrollada por Spivak (2003) muestra la complicidad entre el discurso intelectual y el utilitarismo político-económico occidental. La autora define el proceso de categorización usado por el pensamiento occidental para explicar los fenómenos sociales, como un mecanismo de imposición, ya que este ejercicio discrimina elementos que quedan fuera de las categorías. No sólo se trata de la exclusión de algunas particularidades al momento de categorizar, sino que la categorización misma debe entenderse como un "acto político", pues en el acto de nombrar algunas cosas, se encuentra implícita la negación y la invisibilización de otras. ${ }^{3}$

Ante la interrogante: ¿puede hablar el subalterno?, Spivak (2003) construye una respuesta negativa, acusando las dificultades de las estructuras del conocimiento fundadas en un etnocentrismo occidental que ejerce un tipo de violencia epistémica, a través de la representatividad. Tales prácticas tienen a su vez sustento en el capitalismo internacional,

\footnotetext{
${ }^{2}$ Mujeres, jóvenes y, en menor medida, grupos indígenas no conforman categorías subalternas per se; es necesario acudir a la particularidad de los contextos que les definen, en donde se cruzan otras variables, de clase, educación, territorialidad, etc., para determinar en qué momentos específicos estos grupos constituyen un tipo de subalternidad.

${ }^{3}$ Pese a que la función de la noción de subalternidad es cuestionar la categorización, así como la representatividad o invisibilización que de ésta se derivan, el concepto constituye en sí mismo una categoría; por lo tanto, debe entenderse como un tipo ideal en el sentido weberiano.
} 
que defiende los intereses coloniales de occidente, negando el acceso a los espacios de enunciación a los grupos subalternos. Según Carvalho (2002), la tarea primordial de la teoría postcolonial consiste en luchar por trasladar las enunciaciones elaboradas desde el primer mundo, caracterizadas por ser posiciones fijas y de interés sobre determinados procesos, hacia posiciones plurales del tercer mundo. Plantea relocalizar el origen de la mirada. En palabras del autor, se trata de "conquistar un espacio de enunciación, asegurar un lugar para el discurso [...] en esa batalla por una subjetivación ecuánime” (p. 299).

Por su parte, Beverley (2004) define la subalternidad como antítesis de la autoridad cultural, es decir, opuesta al discurso hegemónico del deber ser. De acuerdo con este autor, los estudios subalternos y los culturales convergen en "la idea de un desplazamiento de la autoridad hermenéutica a la recepción popular” (p. 44). Según explica, estas disciplinas académicas buscan dar voz a la subalternidad, en parte porque el propio academicismo está en deuda tras un largo periodo de exotizar y cosificar a los grupos subalternos. Sin embargo, este mismo esfuerzo por dar voz al subalterno conduce, de manera paradójica, a una falsa representatividad; falsa porque la representatividad produce, forzosamente, subalternidad. De acuerdo con Beverley (2014), el subalterno no puede ser representado, se resiste ante la simbolización. No obstante, vislumbrarle como particularidad subordinada y no como categoría ontológica permite establecer referencias espaciales a partir de formas de territorialidad; metafóricamente se le puede tipificar, desde un sur subordinado, como un norte colonial (Beverley, 2004).

La relevancia de recurrir a los planteamientos de los autores citados es reconocer que las y los subalternos no necesitan ser representados, sino escuchados en sus propios términos; reconocer que su voz es una voz distinta, que tiene la capacidad de generar sus propios conocimientos, de desarrollar su propia consciencia, de autorepresentarse. También es importante reconocer que los movimientos sociales son un mecanismo mediante el cual las expresiones subalternas buscan ser escuchadas. De acuerdo con Valenzuela (2015), los movimientos sociales objetan el control de la historicidad, presentan nuevas proyecciones o transformaciones culturales. En palabras del autor: "Los movimientos sociales actúan como fuerzas culturales que impugnan, resisten a las fuerzas dominantes, desde condiciones y relaciones de subordinación y subalternidad" (Valenzuela, 2015: 40). 
DE LA PALABRA PROHIBIDA A LA VOLUNTAD DE VERDAD: MOVIMIENTO SOCIAL Y ESTADO

Foucault (1992) se cuestiona sobre el peligro de que las personas hablen y sus discursos proliferen de manera indefinida; plantea que: "en toda sociedad la producción del discurso está a la vez controlada, seleccionada y redistribuida por cierto número de procedimientos que tienen por función conjurar los poderes" (Foucault, 1992, p. 5). Desde esta perspectiva, el Estado ejerce poder mediante una "voluntad de verdad", que se proyecta como un discurso hegemónico. La voz subalterna, expresada en movilizaciones sociales, constituye una "palabra prohibida"; es la búsqueda de visibilizar aquello que no se enuncia o que no se hace mediante sus propias formas de enunciación. La política moderna pertenece a un orden de racionalidad occidental, se fundamenta sobre la noción de representatividad; los actores políticos son representantes de diferentes grupos, particularmente de los más alejados de los espacios hegemónicos de enunciación, que manejan las grandes empresas, los actores políticos, los académicos y los medios tradicionales de comunicación.

La palabra prohibida, refiere Foucault (1992), alude a la negación del discurso en un sentido amplio. No se puede hablar de cualquier cosa; existen tópicos prohibidos, bajo determinadas circunstancias, que además se reducen a ciertos grupos hegemónicos o especializados. En este sistema operan distintos tipos de prohibiciones generales: el tabú del tema que se discute y el derecho exclusivo o privilegiado de los sujetos en relación con determinados temas. La voluntad de verdad tiene un soporte institucional que le da fuerza a través de diversas prácticas que legitiman el discurso, a la vez que ejercen sobre otros discursos una especie de presión y un poder de coacción.

Velázquez (2013) plantea recurrir a la noción de voluntad de verdad para observar de qué manera el Estado interviene sobre las movilizaciones sociales, a través de estrategias más sórdidas y complejas que la negociación, como la represión o la aplicación de marcos jurídicos que criminalizan la protesta social. La postura de Velázquez (2013) esboza la figura de un Estado como agente autónomo, compuesto por diversos órganos administrativos, que a su vez manejan un tipo específico de independencia, la cual les confiere la capacidad de perseguir objetivos particulares o diferenciados. Esta definición permite romper con el viejo paradigma de que el Estado es la arena o el campo donde la contienda social tiene lugar, para así contemplarlo como un agente activo en las disputas. Esta visión permite detectar otros mecanismos de control social que se articulan a través del orden del discurso. En palabras del autor, se trata de "mecanismos mediante los cuales se busca dirigir, orientar y desarrollar una población -en sus formas de acción 
colectiva como las protestas- dentro de un territorio determinado” (Velázquez, 2013, p. $6)$.

Otro aspecto importante de reconocer al Estado, como entidad autónoma y no como arena de contienda política, es su situación junto a otros poderes emergentes, según señala Velázquez (2013), pues así es posible superar las viejas nociones de construcción de ideología en manos de los aparatos políticos y gubernamentales, para poder reconocer la centralidad que juegan también los medios de comunicación. El autor señala que al recurrir a los planteamientos de Foucault (1992), se abre la posibilidad de concebir al Estado como un agente compuesto por diversas organizaciones e instituciones, no homogéneas, que actúan en distintas direcciones y buscan redirigir y controlar la protesta social, a través de distintas y complejas "técnicas de acción estatal". En palabras del Velázquez (2013): "los Estados buscan generar múltiples discursos de verdad (prácticas, técnicas, leyes) que permitan a los individuos, grupos y a la sociedad, lograr su desarrollo. Esto a su vez implica necesariamente formas de represión de comportamientos, formas de pensar" (p. 3).

Diversos autores han centrado el análisis de las movilizaciones sociales en los medios de comunicación y particularmente en las tecnologías de redes. Castells (2009) plantea que existen formas emergentes de resistencia, aunadas a la sociedad red; expone que la “acción colectiva de los movimientos sociales" busca generar nuevos códigos en la distribución de la información en red, como forma "resistirse a la programación e interrumpir las conexiones para defender valores e intereses alternativos” (p. 84), de manera que tanto la pregunta de Foucault (1992): ¿QQué hay de peligroso en el hecho de que las gentes hablen y de que sus discursos proliferen indefinidamente?”, como la pregunta de Spivak (2003): “Puede hablar el subalterno?” adquieren un nuevo matiz en el contexto de las resistencias y movilizaciones políticas de la sociedad digital, que apremia ser analizado.

Nos encontramos, pues, frente a la emergencia de nuevas formas de enunciación, nuevas formas de expresión y de distribución de lo expresado; nuevas formas de resistencia, pero también frente a nuevas formas de imposición discursiva y dominación política. En otras palabras, estamos frente a nuevas formas de relación entre los discursos hegemónicos y subalternos, en donde una diversidad de actores se suma a la construcción discursiva de la realidad política a través de contenidos audiovisuales, gracias a las facilidades que provee el uso de redes sociodigitales, vinculadas con artefactos de comunicación-producción audiovisual. 


\section{REDES SOCIODIGITALES Y VIDEOACTIVISMO EN LAS MOVILIZACIONES POLÍTICAS}

Distintos autores han retomado perspectivas gramscianas para analizar las contiendas discursivas en el contexto de las redes sociodigitales. Miles (2013) plantea que los discursos de la clase dominante empiezan a ser disputados mediante narrativas contrahegemónicas que cuestionan su legitimidad, sin embargo, concluye que estas narrativas son debatibles ya que pertenecen a grupos con intereses fragmentados. Dyczok (2014) señala que a pesar de las particularidades de las disputas políticas nacionales contenidas en plataformas digitales, éstas se adscriben a una tendencia global y son ampliamente influenciadas por tal realidad; de esta manera, las reivindicaciones y los discursos contrahegemónicos locales mantienen un vínculo con tendencias generales que comparten características y se observan en distintos países.

Según Castells (2012, 2009), las nuevas formas de asociación derivadas del uso de internet pueden tornarse acciones reivindicativas, debido a que las redes facilitan la comunicación autónoma de los individuos, frente a un gobierno y unos "medios de comunicación". Las redes sociodigitales han marcado una pauta importante en las formas de participación social, ya que su naturaleza fragmenta en distintos niveles el ejercicio del poder a través de la comunicación horizontal, lo cual facilita los procesos de autocomunicación de masas, que a su vez dan lugar a la acción colectiva. Se trata de un nuevo contexto de "comunicación digital" que amplía los repertorios de participación ciudadana (Castells, 2012).

Las nuevas formas de conectividad, así como las nuevas formas de agencia, expresión o presencia política, mediadas por el uso de plataformas digitales, constituyen un marco conceptual adecuado para el análisis de los movimientos sociales en la era de internet. Para destacar su valor heurístico, es necesario matizar algunos de los procesos específicos que le dan consistencia empírica. El videoactivismo destaca en la configuración de los repertorios de participación política (Treré, 2015); es un proceso mediático potenciado por el uso de redes sociales digitales, pero también portador de discursos contrahegemónicos: constituye un proceso que favorece la conectividad, la agencia, la expresión y la presencia política de grupos subalternos.

En el videoactivismo, Montero y Candón (2015) observan nuevas formas de acción política, alternativas a las narrativas mediáticas de grupos hegemónicos; lo consideran un elemento importante en la configuración de nuevas formas de acción política, que trasciende a las tradicionales formas de movilización colectiva. En el análisis que desarrollan Montero y Candón (2015), éstos plantean que el videoactivismo viene de 
algunas décadas atrás y se inscribe en un nuevo paradigma político-cultural, como "acto de resistencia" de las nuevas formas de la "cultura política" (Montero y Candón, 2015). Como práctica política, el videoactivismo intenta complejizar, desde esta dimensión, la producción y la creación cultural, principalmente mediante la búsqueda de alternativas de producción orientadas al crowdfounding y los canales alternativos de distribución. De tal manera, el videoactivismo es capaz de aumentar los “espacios de enunciación” e implementar estrategias de inclusión y mecanismos de dialogo.

Es importante destacar que si bien los videoactivistas han tenido presencia en las movilizaciones sociales desde la década de los sesenta, en este momento histórico, que deviene en la implementación y uso intensivo de las redes sociodigitales, así como de las Tecnologías de la Información y la Comunicación (TIC); en general, el videoactivismo ha encontrado nuevos canales de distribución con alcances multitudinarios. Los videoactivistas, una generación de voces colectivas que visibiliza la experiencia como mecanismo de empoderamiento (Montero y Candón, 2015), se han propuesto, desde sus orígenes, partir de la capacidad de producir una comunicación autónoma y, mediante el desarrollo de plataformas digitales, han encontrado los canales idóneos de distribución; su acción se inscribe como uno de los elementos de mayor relevancia en la autocomunicación de masas.

Un ejemplo importante de esto, de acuerdo con Treré (2015), son las protestas del movimiento \#YoSoy132, durante el proceso electoral federal de 2012 en México, cuando un grupo de estudiantes de la Universidad Iberoamericana, en un ejercicio de videoactivismo, subió a YouTube archivos en los que mostraba su enfrentamiento con el entonces candidato a la presidencia de la República, Enrique Peña Nieto. Además de éstos, otro archivo importante fue el video donde los estudiantes mostraron sus credenciales, para contradecir las versiones de los medios hegemónicos, según los cuales la mencionada agitación había estado a cargo de personas ajenas a la Institución. Estas acciones derivaron en un movimiento social que dejó ver que la juventud en México puede asumirse como actor político, cuyos repertorios de participación no se inscriben de manera pasiva con los procesos institucionales electorales, pero tienen un vínculo con el uso de las tecnologías de comunicación, en particular con la producción audiovisual.

Esta producción no se limita al video; también las imágenes cobran gran relevancia desde el ejercicio fotográfico, la creación de GIF y de memes humorísticos. Se trata, para Reguillo (2015), de la "autoproducción de representaciones alternativas y compartidas" que, en una supuesta normalidad de los poderes autoritarios, introducen temáticas ignoradas o silenciadas por el discurso hegemónico neoliberal, promovido por 
los medios de comunicación. De acuerdo con la autora, toda esta alegoría, manifiesta en las redes y en las calles, representa nuevos procesos de colectividad que definen una dimensión postpolítica que va más allá de las formas tradicionales de hacer política formal.

La utilización de redes sociodigitales en el activismo y la participación política tiene como base la producción y distribución de materiales audiovisuales en relación con actos de resistencia. La masificación y el uso común de celulares que cuentan con una cámara capaz de generar archivos audiovisuales ha potenciado la práctica del videoactivismo en múltiples formas, desde la construcción de materiales que proyectan discursos contrahegemónicos, hasta sencillas expresiones de denuncia de irregularidades o abuso de autoridad, que se distribuyen en las redes sociodigitales.

En la actualidad, la culturalización de los movimientos sociales se vuelve más evidente, a la vez que se incorpora en discursos académicos que destacan aspectos singulares como el juego y el humor, a través de los cuales se manifiesta la capacidad de imaginar y reinventar el mundo (Benson, 2015). Mediante cargas humorísticas, se sopesan las difíciles condiciones de vida impuestas por la racionalidad tecnocrática de la política. Treré (2015) explica cómo el videoactivismo de la era digital adquiere este peculiar matiz, de manera que gran parte de la crítica audiovisual que circulaba en redes en torno al proceso electoral de 2012 se configuraba con una gran carga humorística. Un sexenio más tarde, en el proceso electoral de 2018, el videoactivismo vertebró la expresión vernácula de las y los electores, pero, al mismo tiempo, fue apropiado por actores políticos que intentaron imitar el carácter orgánico de estas creaciones audiovisuales. En ocasiones, las producciones resultaban muy rebuscadas, de modo que evidenciaban la intencionalidad de los montajes y sus contenidos; otras veces, eran muy orgánicas, conectaban con los electores y los candidatos.

En México, los procesos electorales del 2012 y 2018 se constituyeron en una especie de arena de lucha mediática, en la que, por una parte, los medios tradicionales desplegaron una serie de estrategias para colocar a los candidatos, mientras, por otra, la sociedad civil organizada, particularmente las y los jóvenes intervinieron creativamente, sobre todo a través de la producción audiovisual, con lo cual generaron y multiplicaron los espacios de enunciación política y negociaron las representaciones mediáticas de los candidatos y de los partidos, demostrando un deseo de participación y de dialogo, un deseo de participar en la construcción de las representaciones mediáticas de sus propias experiencias políticas. 
Para Benson (2015), la presencia de las movilizaciones en el contexto de la sociedad red constituye el ejemplo de un conjunto de agenciamientos emergentes, frente al desplome de la representatividad política; señala que estas movilizaciones reintroducen el juego como un valor importante con la capacidad de reimaginar la sociedad. El autor explica que la creación de contenidos audiovisuales está expandiendo las capacidades de jugar, en formas hasta hace algunos años impensables, permitiendo la experimentación con nuevas estructuras, nuevos sentidos y nuevas asociaciones simbólicas. Se trata de formas lúdicas que buscan, mediante el contagio emocional de la colaboración, experimentar con nuevas formas de satisfacción, permitirse reimaginar y reinventar la realidad social (Benson, 2015).

\section{TECNOPOLÍTICA, ENTRE LA VOLUNTAD DE VERDAD Y LA CONDICIÓN SUBALTERNA}

Entre los años 2012 y 2013, distintos acontecimientos reivindicativos sacudieron al mundo y con esto las interpretaciones académicas. Frente a este contexto, los estudiosos de los movimientos sociales buscaron reinventarse conceptualmente. El \#YoSoy132 en México (Estrada, 2014; Morales, 2014; Valenzuela, 2015); el \#OccupyWallStreet en Estados Unidos de América (Benson, 2015); el \#15M en España en 2011 (Calvo, Gómez-Pastrana y Mena, 2011); el \#PaseLivre en Brasil (Spiro y Monroy-Hernández, 2016) y, por supuesto, la Primavera Árabe (González-Quijano, 2011). Estas eventualidades presentaron una serie de afinidades muy generales que deslumbraron a los estudiosos, como el hecho de que tendían a cierta descentralización organizacional, es decir, carecían de liderazgos (sindicales, en su mayoría), estaban compuestos por grupos heterogéneos y presentaban una organización rizoma, sin jerarquías aparentes; por supuesto, su afinidad más común era el uso de redes sociodigitales en la difusión de información, convocatorias, y la identificación entre los manifestantes.

A partir de las características más generales que resultaron afines, todas estas eventualidades se incluyeron en un mismo marco interpretativo; muchas de las reflexiones presentaban grandes omisiones en torno a la particularidad de los contextos sociales y políticos en los que tuvieron lugar. Aún más, otras tantas interpretaciones omitieron las estrategias de los poderes políticos y su vínculo con el uso de redes sociodigitales y los resultados de cada una de estas movilizaciones. En el caso de los procesos electorales mexicanos a los que hemos dado seguimiento, apreciamos dos características generales. En 2012, la emergencia del \#YoSoy132 marcó una irrupción significativa. Aunque el principal adversario del movimiento era Televisa, como actor 
protagónico de la hegemonía mediática, en gran medida subyacía un rechazo al candidato del PRI, Enrique Peña Nieto; de hecho, el origen del movimiento se remonta al enfrentamiento entre estudiantes y el equipo de campaña de dicho candidato, como hemos descrito líneas arriba.

A la postre, no sólo el vocero del movimiento obtuvo un lugar protagónico en un noticiero de Televisa, sino que también el candidato del PRI resultó ganador de las elecciones, gracias a una estrategia mediática que recurrió a la narrativa aparentemente oxidada de las telenovelas mexicanas, personificando a Enrique Peña Nieto como un galán joven, cuya esposa literalmente había protagonizado distintos papeles en estas narrativas televisadas. A la vez, se recurrió a la construcción de una campaña negra en contra del entonces candidato opositor Andrés Manuel López Obrador, que se difundió mayormente a través de videos en YouTube, de manera extra oficial, aprovechando la escasa regulación del, en esos años, Instituto Federal Electoral sobre el uso de medios digitales en tiempos de campaña.

Seis años más tarde, el candidato López Obrador, que había sido derrotado en 2012, contendió nuevamente por la presidencia de la República mediante la estrategia descrita. En esta ocasión, las redes sociodigitales se habían instaurado como parte fundamental de la ecología mediática y, por supuesto, de la interacción, diálogo y discusión política. De esta manera, el proceso electoral de 2018, rebasó por mucho la atrasada regulación del tiempo asignado a los partidos políticos en radio y televisión, así que las campañas electorales se desarrollaron de manera orgánica, con nula regulación en redes sociodigitales, destacando plataformas como Facebook y Twitter. En ausencia de un movimiento como \#YoSoy132, dicho candidato capturó toda expresión de oposición y reivindicación política.

A través de múltiples estrategias, que incluían el uso de memes, videoactivismo e interacciones en redes, la tecnopolítica se hizo presente, fortaleció la imagen del candidato opositor y lo posicionó hasta asegurar su triunfo. Esta transición entre dos procesos electorales nos permite observar que la tecnopolítica se desarrolla entre discursos hegemónicos y narrativas subalternas. Simultáneamente, nos permite apreciar cómo las movilizaciones subalternas se insertan en una dinámica discursiva, que, si bien les da acceso a espacios de diálogo, termina por transformar su visión y la estructura de su discurso para adaptarse a los parámetros en los que tradicionalmente las clases dominantes desarrollan el propio.

El movimiento \#YoSoy132 perdió fuerza reivindicativa por cooptación e integración. Un sexenio más tarde, muchos de sus integrantes se sumaron a la campaña 
del partido Movimiento de Regeneración Nacional (MORENA), en apoyo al candidato Andrés Manuel López Obrador. El caso más emblemático es el del antiguo vocero del movimiento, Antonio Attolini, quien tras presidir un programa de noticias en Televisa, durante el proceso electoral de 2018 se convirtió en vocero de dicho candidato. Tanto el partido como su candidatura a la presidencia de la República, representaron la oposición política en este proceso. Sin embargo, tras resultar electos, en sus primeros dos años de gobierno han recurrido a distintas estrategias de modelaje de la opinión pública, mediante el uso estratégico de redes sociodigitales; estrategias que han sido ampliamente visibilizadas por las y los estudiosos de redes y tecnopolítica del Signa_Lab, dirigido por la investigadora Rossana Reguillo.

\section{CONCLUSIONES}

Los movimientos sociales tienen una presencia constante que se articula sobre una relación compleja entre el Estado y la sociedad civil organizada, con la participación de otros actores vinculados a los medios de comunicación; constituyen reivindicaciones que permiten a los grupos subalternos expresar demandas frente a grupos hegemónicos. Buscan una transformación con base en procesos de subjetivación, a partir de los cuales reivindican sectores subalternos, cuya voz ha sido silenciada por la representatividad política, las narrativas mediáticas y los discursos académicos.

La sociedad contemporánea experimenta procesos de híper-tecnificación en los que la producción y el desarrollo tecnológico, como base material de las relaciones sociales, juegan un papel fundamental. Las condiciones materiales de la vida contemporánea son cada vez más complejas y tecnificadas, de manera que su producción y apropiación en los distintos procesos sociales no puede jugar un papel secundario en las reflexiones e investigaciones. La centralidad protagónica, que se ocupa tanto en las expresiones de dominación como en las de resistencia, exige una mirada desde los estudios culturales, los estudios subalternos y postcoloniales.

La construcción de sentido por parte de los dueños de medios de producción no ha perdido su hegemonía; sin embargo, el actual panorama de la ecología mediática permite la formación de nuevos procesos de resignificación y nuevas formas de consumo activo, a través de la creación de contenidos audiovisuales como el videoactivismo, los memes o la simple interacción entre usuarios de plataformas como Facebook y Twitter. Por lo tanto, las tecnologías de comunicación, y particularmente las redes sociodigitales, 
devienen dispositivos culturales, en la medida que las y los sujetos les otorgan el atributo de involucrarse en los procesos de apropiación y enunciación de su entorno político.

La naturaleza que adquiere la producción de los nuevos artefactos tecnológicos que hacen posible una parte importante de las interacciones sociales tiende a fragmentar el ejercicio del poder comunicacional en términos discursivos y facilita la ampliación de los espacios de enunciación subalterna. Los ciudadanos incrementan sus repertorios de participación política, mediante la producción y distribución de materiales audiovisuales, y fortalecen su capacidad de negociar la construcción de representaciones mediáticas sobre el contexto político; simultáneamente, los actores políticos desarrollan nuevas y sofisticadas estrategias de dominación discursiva, mientras la disputa política, los discursos hegemónicos y contrahegemónicos se complejizan en nuevas arenas digitales.

\section{REFERENCIAS}

Barandiaran, X., Calleja-lópez, A., Monterde, A., Aragón, P., Linares, J., et al. (2017). Decidim: redes políticas y tecnopolíticas para la democracia participativa. Recerca. Revista de pensament i anàlisi, 21, pp. 137-150.

Benson Silva, P. (2015). Occupy Wall Street. Necedades, hacks y nuevas coyunturas: registro de un repertorio táctico ampliado. En VALENZUELA ARCE, J. (coord.), El sistema es antinosotros. Culturas, movimientos y resistencias juveniles (pp. 103-128). México: UAM, El Colegio de la Frontera Norte, Gedisa.

Beverley, J. (2004). Subalternidad y representación. Debates en teoría cultural. Madrid: Iberoamericana.

Carvalho, J. J. (2002). La mirada etnográfica y la voz subalterna. Revista Colombiana de Antropología, 38, pp. 287-328. Recuperado de: https://bit.ly/3h0JYkP.

Calvo, K., Gómez-Pastrana, T. y Mena, L. (2011). Movimiento 15M: ¿quiénes son y qué reivindican? Zoom Político, Especial 15-M. Recuperado de: https://bit.ly/2Dx1nUD.

Castells, M. (2009). Comunicación y poder. Madrid: Alianza Editorial . (2012). Redes de indignación y esperanza. Los movimientos sociales en la era de internet. Madrid: Alianza Editorial.

SpIVAK, G. (2003). ¿Puede hablar el subalterno? Revista Colombiana de Antropología, 39, pp. 297-364.

De Sousa Santos, B. (2011). Epistemologías del sur. Utopía y Praxis Latinoamericana. Revista Internacional de Filosofía Iberoamericana y Teoría Social 16(54) pp. 17-39. . (2010). Para descolonizar Occidente: más allá del pensamiento abismal. Buenos Aires: Consejo Latinoamericano de Ciencias Sociales (CLACSO), Prometeo Libros. 
DYCZOK, M. (2014). Information wars: hegemony, counter-hegemony, propaganda, the use of force, and resistance. Recuperado de: https://bit.ly/3bukHi1.

Estrada, M. (2014). Sistema de protesta: política, medios y el \#YoSoy132. Sociológica, 29(82), pp. 83-123. Recuperado de: https: / bit.ly/32Z6jul.

Foucault, M. (1992). El orden del discurso. Buenos Aires: Tusquets Editores.

GAlindo CÁCERes, J. (2006). Cibercultura. Un mundo emergente y una nueva mirada. México: CONACULTA.

GiRALDO, S. (2003). Nota introductoria a ¿Puede hablar el subalterno? Revista Colombiana de Antropología, 39, pp. 297-364.

GONZÁlEZ-QuiJANO, Y. (2011). Las revueltas árabes en tiempos de transición digital. Mitos y realidades. Nueva sociedad, 235, septiembre-octubre. Recuperado de: https: / / bit.ly/3lWjDbm.

Gramsci, A. (1987). Algunos temas sobre la cuestión meridional. En Macciocchi, M. (Ed.), Gramsci y la revolución de occidente (pp. 289-310). México: Siglo XXI Editores.

. (1967). La formación de los intelectuales. México: Grijalbo.

GuHA, R. (2002). Las voces de la historia y otros estudios subalternos. Barcelona: Crítica.

Mattoni, A. y Treré, E. (2014). Media practices, Mediation processes, and Mediatization in Study of Social Movements. Comunication Theory, 24, pp. 252271. Doi: $10.1111 /$ comt. 12038

Milan, S. y Treré, E. (2017). Big Data from the South: The Beginning of a Conversation We Must Have. SSRN Electronic Journal, January. DOI: $10.2139 / \operatorname{ssrn} .3056958$

Miles, L. (2013). Gramsci, Counter-hegemony and Labour Union-Civil Society Organization Coalitions in Malaysia. Recuperado de: https://bit.ly/2GAu843.

Modonesi, M. (2002). Subalternidad. En Conceptos y fenómenos fundamentales de nuestro tiempo. México: Universidad Nacional Autónoma de México (UNAM). Recuperado de: https: / / bit.ly/332XEa1.

Montero, D. y CANDÓn, J. (2015). Sobre las imágenes del 15M. El videoactivismo como experimentación cultural y política. En SIERrA, F. y MONTERO, D. (Eds.), Videoactivismo y movimientos sociales. Teoría y praxis de las multitudes conectadas (pp. 832-457) Barcelona: Gedisa.

Morales, F. (2014). El movimiento estudiantil \#YoSoy132. Antología hemerográfica. México: Universidad Iberoamericana.

Reguillo, R. (2015). \#Ocupalascalles \#Tomalasredes. Disidencia, insurgencias y movimientos juveniles: del desencanto a la imaginación política. En VALENZUELA ARCE, J. (coord.), El sistema es antinosotros. Culturas, movimientos y resistencias juveniles (pp. 29-60). México: UAM, El Colegio de la Frontera Norte, Gedisa 
Spiro, E. y Monroy-HernándeZ, M. (2016). Shifting Stakes: Understanding the Dynamic Roles of Individuals and Organizations in Social Media Protests. Plos One, 11(10). Recuperado de: https: / / bit.ly/3bvcwC1.

Tilly, C. (2010). Los movimientos sociales 1768-2008. Desde sus orígenes a Facebook. Barcelona: Crítica.

Toret Medina, J. (2013). Tecnopolítica: la potencia de las multitudes conectadas. El sistema red 15M, un nuevo paradigma de la política distribuida. Barcelona: Universitat Oberta de Catalunya.

Touraine, A. (2011). ¿Podremos vivir juntos? México: FCE. - (2006a). Los movimientos sociales. Revista Colombiana de Sociología, 27, pp. 255-278. Recuperado de: https://bit.ly/3jUN5wN. . (2006b). Crítica de la modernidad. México: Fondo de Cultura Económica (FCE).

Treré E. (2015). Ecología del videoactivismo contemporáneo en México: alcances y limitaciones de las prácticas de resistencia en las redes digitales. En SIERRA, F. y Montero, D. (Eds.), Videoactivismo y movimientos sociales. Teoría y praxis de las multitudes conectadas (pp. 167-187) Barcelona: Gedisa.

VAlenzuela Arce, J. (2015). Las voces de la calle... y de las redes sociales, los movimientos juveniles y el proyecto neoliberal. En VALENZUELA ARCE, J. (coord.), El sistema es antinosotros. Culturas, movimientos y resistencias juveniles (pp. 29-60). México: UAM, El Colegio de la Frontera Norte, Gedisa.

VELÁzQUEZ, M. (2013). Los movimientos sociales contemporáneos y el análisis del poder estatal. Intersticios Sociales, 6, pp. 1-22. Recuperado de: https: / / bit.ly/2EUNNLL.

Ventura, A. (2018). Prefacio. En Gambetta, D. (coord.), Politica, cultura algoritmica e conflitti al tempo dei big data. Génova: DEditore. 